\title{
UM ESTUDO DE RISCO DAS COOPERATIVAS DE CRÉDITO BRASILEIRAS COM BASE NO BETA CONTÁBIL
}

\author{
A RISK STUDY OF BRAZILIAN CREDIT UNIONS \\ BASED ON ACCOUNTING BETA
}

\section{IGOR COSTA TEIXEIRA}

Universidade Federal do Rio de Janeiro. Endereço: Avenida Pasteur $250 \mid$ Urca | 22.290-240 | Rio de Janeiro/RJ | Brasil.

(1) http://orcid.org/0000-0002-9423-7783

igorct718@gmail.com

\author{
VINICIUS MOTHÉ MAIA \\ Universidade Federal do Rio de Janeiro. Endereço: Avenida Pasteur $250 \mid$ \\ Urca | 22.290-240| Rio de Janeiro/RJ | Brasil. \\ (D) http://orcid.org/0000-0001-6156-3104 \\ vmaia@facc.ufrj.br
}

RUDOLPH FABIANO ALVES PEDROZA TEIXEIRA

Universidade Federal do Rio de Janeiro. Endereço: Avenida Pasteur 250 | Urca | 22.290-240 | Rio de Janeiro/RJ | Brasil.

(D)http://orcid.org/0000-0001-5325-5267

rudolphteixeira@gmail.com

\begin{abstract}
RESUMO
O cooperativismo de crédito é especialmente importante para diversos municípios brasileiros que não dispõem de acesso ao crédito bancário. Torna-se relevante analisar como os indicadores contábeis propostos pelo sistema PEARLS se relacionam com o risco das cooperativas, impactando diretamente o desenvolvimento de áreas carentes. O objetivo desta pesquisa foi investigar se os indicadores contábeis propostos pelo sistema PEARLS apresentam relação com o risco das cooperativas de crédito brasileiras. Caso tal hipótese seja confirmada, pode-se afirmar que as informações contábeis contidas nesses indicadores são úteis para auxiliar seus usuários na tomada de decisões. Para tanto, foi construído um modelo econométrico tendo como variável dependente o beta contábil das cooperativas (risco) explicado pelos indicadores contábeis PEARLS. Os resultados apontaram para uma relação positiva e significativa entre o risco de uma cooperativa e seus depósitos totais, sua provisão para estimativa de créditos de liquidação duvidosa (inadimplência), e suas despesas operacionais. Além disso, todas as variáveis foram relevantes para explicar o risco das cooperativas de crédito. Isso sugere que as informações contábeis presentes nos indicadores PEARLS são úteis para auxiliar seus usuários a tomarem decisões quanto à avaliação de risco dessas entidades. Essa constatação é relevante, pois a eventual insolvência das cooperativas de crédito impacta não somente os cooperados, mas também as localidades onde estão inseridas.
\end{abstract}

Palavras-chave: Cooperativismo. Cooperativa de Crédito. Beta Contábil. Risco. 


\begin{abstract}
Credit unions are essential for many Brazilian municipalities with no access to bank credit. It is important to analyze how the PEARLS system's accounting indicators are related to the risk of cooperatives, directly impacting the development of deprived areas. This research aimed to investigate whether the accounting indicators proposed by the PEARLS system are related to the risk of Brazilian credit unions. If this hypothesis is confirmed, it can be said that the accounting information contained in these indicators is useful to assist its users in decision making. To this end, an econometric model was built using the cooperative accounting beta (risk) as the dependent variable explained by the PEARLS accounting indicators. The results indicate a positive and significant relationship between the risk and total deposits of a cooperative, its provision for the estimate of doubtful receivables (default), and its operating expenses. Furthermore, all variables were relevant to explain the risk of credit unions, suggesting that the accounting information present in the PEARLS indicators is useful to assist its users in decision-making regarding these entities' risk assessment. This finding is relevant because cooperatives' potential insolvency impacts not only the members but also their locations.
\end{abstract}

Keywords: Cooperativism. Credit Union. Accounting Beta. Risk.

\title{
1 INTRODUÇÃO
}

As cooperativas de crédito são instituições financeiras sem fins lucrativos que prestam serviços financeiros exclusivos aos seus membros. Os cooperados (ou associados) obtêm acesso a diversos produtos similares aos oferecidos pelos bancos, como conta corrente, cartão de crédito, empréstimos e financiamentos. Ao mesmo tempo em que o associado é dono da cooperativa, ele também é seu cliente, participando inclusive da repartição de eventuais resultados positivos ou negativos gerados pelas operações dessa entidade (Banco Central do Brasil, 2018).

No Brasil, a importância social das cooperativas de crédito reside no fato de existirem diversos municípios sem acesso ao tradicional crédito bancário. Essas sociedades possibilitam aos moradores dessas localidades um acesso alternativo a recursos financeiros que podem ser utilizados para consumo ou pequenos investimentos (Jacques \& Gonçalves, 2016).

De acordo com Bressan, Braga, Bressan e Resende Filho (2011), um dos grandes desafios das cooperativas de crédito na atualidade é criar mecanismos de gestão que: a) sejam compatíveis com seu modelo administrativo; b) atendam às exigências regulatórias do Banco Central do Brasil (BACEN); e c) estejam de acordo com seus princípios doutrinários.

Nesse contexto, o Conselho Mundial do Cooperativismo de Poupança e Crédito (World Council of Credit Unions - WOCCU), uma agência internacional para promoção do cooperativismo de crédito, criou o sistema PEARLS no final da década de 1980. Esse sistema surgiu como uma adaptação do U.S. CAMELS, que representa um conjunto de indicadores de desempenho utilizado nos Estados Unidos para o monitoramento de instituições financeiras. O PEARLS é o acrônimo para um grupo de indicadores financeiros de avaliação das atividades operacionais das cooperativas de crédito, quais sejam: Proteção, Efetiva estrutura financeira, qualidade dos Ativos, taxas de Retorno e custos, Liquidez, e Sinais de crescimento (Bressan et al., 2011).

O sistema PEARLS busca: a) auxiliar na análise gerencial das cooperativas de crédito, para mitigar problemas institucionais sérios; b) criar uma linguagem financeira universal entre essas instituições e o seu público externo, possibilitando a uniformidade e a comparabilidade ao longo do tempo; e c) facilitar a supervisão das cooperativas de crédito por meio de seus dados contábeis (WOCCU, 2019). 
Desse modo, verifica-se que o sistema PEARLS é importante para monitorar as cooperativas de crédito. Isso se deve principalmente ao prejuízo representado por potenciais insolvências dessas entidades. Prejuízo esse não somente aos seus associados, mas também a uma vasta gama de envolvidos, como funcionários, prestadores de serviços, fornecedores e a própria economia da região em que se encontram. Mesmo o sistema PEARLS funcionando como um verdadeiro "painel de voo", orientando e guiando gestores, cooperados e órgãos fiscalizadores sobre o desempenho das cooperativas (Kaplan e Norton, 1993), não se sabe se seus indicadores financeiros possuem qualidade contábil suficiente para predizer o risco de crédito das cooperativas.

Tendo em vista o papel desempenhado pelas cooperativas de crédito em diversos municípios, torna-se relevante analisar como a qualidade dos indicadores contábeis propostos pelo sistema PEARLS impacta o risco dessas instituições, o que afeta a vida dos cooperados e as regiões onde estão inseridas.

Assim, o objetivo deste trabalho é investigar se os indicadores contábeis propostos pelo sistema PEARLS apresentam relação com o risco das cooperativas de crédito brasileiras. Caso tal hipótese seja confirmada, pode-se afirmar que as informações contábeis contidas nos indicadores são úteis para que seus usuários as utilizem na tomada de decisões. Para tanto, será usado o chamado beta contábil (explicado detalhadamente na Seção 2.3) como proxy para risco, conforme proposto por Beaver e Manegold (1975) e Damodaram (1997), já que as cooperativas são entidades de capital fechado que não negociam em bolsa de valores.

\section{REFERENCIAL TEÓRICO}

\subsection{Cooperativas de Crédito}

As cooperativas de crédito, reguladas pela Lei n ${ }^{\circ} 5.764$, de 16 de dezembro de 1971, são definidas como sociedades de pessoas com forma e natureza jurídica próprias, de natureza civil, não sujeitas a falência, e constituídas para prestar serviços aos associados (Lei no 5.764, 1971). Mais especificamente, o objetivo central dessas instituições é prestar serviços financeiros aos seus cooperados de forma igualitária e solidária (Pagnussatt, 2004). Além disso, elas auxiliam na diminuição das desigualdades sociais, facilitando o acesso ao crédito e a diversos serviços similares aos bancários, difundindo o espírito de cooperação em prol do bem-estar social (Almada, Abreu, Cunha, Silva Filho, 2011).

O cooperativismo refere-se a um movimento voltado às pessoas e não ao lucro, ou seja, seu foco repousa na prestação de serviços aos seus associados. Assim, em caso de sobras de recursos (resultados positivos entre os ingressos e dispêndios), estes deverão ser devolvidos aos cooperados proporcionalmente às suas operações com a cooperativa no exercício financeiro (Lei $\left.\mathrm{n}^{\mathrm{o}} 5.764,1971\right)$.

Originalmente, para que as cooperativas de crédito fossem constituídas, eram necessárias no mínimo 20 pessoas. Todavia, com o novo Código Civil Brasileiro, essa quantidade não é mais exigida, sendo necessária apenas membros suficientes para compor o quadro de administração, observando-se futuras renovações desse quadro. O artigo $6^{\circ}$ da Lei $n^{\circ} 5.764$ de 1971 mostra a classificação das sociedades cooperativas, já com suas descrições atualizadas pelo novo Código Civil, conforme a Tabela 1. 
Tabela 1

Classificação das cooperativas de crédito

\begin{tabular}{c|l}
\hline Classificação & \multicolumn{1}{c}{ Descrição } \\
\hline Singulares & $\begin{array}{l}\text { Constituídas pelo número mínimo de vinte pessoas físicas. Com o } \\
\text { novo Código Civil Brasileiro, porém, esse número mínimo deixou de } \\
\text { existir, sendo necessário apenas que haja membros suficientes para } \\
\text { compor o quadro de administração, levando em conta futuras } \\
\text { renovações. }\end{array}$ \\
\hline Centrais ou federações de cooperativas & $\begin{array}{l}\text { Constituídas por no mínimo três singulares, podendo admitir } \\
\text { associados individuais em casos excepcionais. }\end{array}$ \\
\hline Confederações de cooperativas & $\begin{array}{l}\text { Constituídas por pelo menos três federações de cooperativas ou } \\
\text { cooperativas centrais, da mesma ou de diferentes modalidades. }\end{array}$ \\
\hline
\end{tabular}

Fonte: Silva, Cardoso, Martins, Marena e Oliveira (2018) e Lei no 5.764 (1971).

De acordo com a Organização das Cooperativas do Brasil (OCB) (2019), os princípios do cooperativismo são: adesão voluntária e livre, gestão democrática, participação econômica dos membros, autonomia e independência, educação, formação e informação, intercooperação, e interesse pela comunidade.

Segundo Bressan, Braga, Bressan e Resende Filho (2010), um dos grandes desafios das cooperativas de crédito atualmente é a criação de modelos gerenciais que respeitem suas características administrativas e que, simultaneamente, atendam às exigências do BACEN. Nesse sentido, Bressan et al. (2010); Bressan et al. (2011) e Bressan, Bressan, Oliveira e Braga (2014) propõem que seja adotado o sistema PEARLS de indicadores como instrumento para a avaliação operacional das cooperativas brasileiras. Essa sugestão se deve, principalmente, pelo impacto negativo que uma avaliação de risco mal feita nessas entidades pode proporcionar à sociedade e seus associados.

Esse sistema nada mais é que um conjunto de indicadores financeiros que permitem identificar quando uma cooperativa de crédito se encontra em dificuldades financeiras, evidenciando as causas desse problema (Vasconcelos, 2006). Atualmente, o sistema PEARLS é adotado em 97 países distribuídos por todos os continentes, sendo utilizado para o gerenciamento de risco dessas instituições (Bressan et al., 2011).

\subsection{Qualidade da Informação Contábil e Indicadores Financeiros}

A qualidade da informação contábil refere-se à prestação de informações úteis sobre uma entidade aos seus usuários externos (Paulo, 2007). Segundo Dechow, Ge e Schrand (2010), para que as informações contábeis sejam úteis aos seus usuários, elas devem possuir três importantes características de qualidade, a saber: relevância, informatividade e capacidade de mensurar desempenho. A primeira avalia se a informação contábil possibilita que decisões importantes sejam tomadas. A segunda refere-se à capacidade da contabilidade de informar sobre o desempenho da firma. E a terceira implica a habilidade do sistema contábil em mensurar a performance da entidade (Duarte \& Lucena, 2018).

Uma das maneiras de verificar se a informação contábil reportada pelas empresas é de qualidade reside na utilização de indicadores financeiros construídos com base nas demonstrações contábeis (Paulo, 2007). Assim, caso os indicadores financeiros contribuam para a explicação de um determinado fenômeno, pode-se considerar que a informação contábil é de qualidade (Duarte \& Lucena, 2018). No Brasil, a pesquisa sobre a qualidade da informação contábil ainda possui grande potencial de desenvolvimento, pois concentra-se em empresas listadas em bolsa de valores.

Gonçalves e Lemes (2018) recentemente verificaram o efeito do reconhecimento dos gastos com pesquisa e desenvolvimento (P\&D) sobre a qualidade da informação contábil de companhias abertas brasileiras de alta tecnologia entre 2008 e 2015. Os autores constataram que o gasto em $\mathrm{P} \& \mathrm{D}$ reconhecido como despesa e o gasto ativado fornecem informações úteis aos investidores. 
Vallim, Macedo e Kolozsvari (2019), avaliaram a qualidade da informação contábil com base nas diferenças de alongamento dos accruals em sua capacidade preditiva de fluxos de caixas futuros de 168 empresas não financeiras de capital aberto listadas na [B] ${ }^{3}$ em 2017. Os autores concluíram que a capacidade preditiva dos accruals está inversamente relacionada com seu alongamento, isto é, quanto menos alongados forem os accruals, melhor será a qualidade da informação contábil. Quanto mais alongados, pior será a qualidade da informação oriunda da contabilidade.

Já Santos, Guimarães e Macedo (2019), com base em uma amostra de 727 observações de empresas não financeiras no período de 2010 a 2017, analisaram o impacto da agressividade tributária na qualidade das informações contábeis no Brasil. Os resultados mostraram que, quanto maior as Book-Tax Differences (BTD) e menor a Effective Tax Rate (ETR), menor a capacidade informacional do Lucro Líquido por Ação (LLA). Sendo assim, concluiu-se que a agressividade tributária capturada tanto pela BTD quanto pela ETR reduz a capacidade informacional do lucro, prejudicando a relevância das informações contábeis para o mercado brasileiro de capitais.

Quanto a estudos que abordaram indicadores financeiros no Brasil, Bressan et al. (2010) construíram indicadores contábeis para as cooperativas de crédito brasileiras utilizando o Plano Contábil das Instituições Financeiras do Sistema Financeiro Nacional (COSIF). O estudo inovou ao utilizar o sistema, nunca antes usado no país, com o objetivo de auxiliar gestores e demais interessados na obtenção de informações gerenciais sobre as cooperativas de crédito.

Por sua vez, Bressan et al. (2011) aplicaram o sistema PEARLS à realidade brasileira com o objetivo de analisar a insolvência das cooperativas de crédito filiadas ao Sistema de Cooperativas de Crédito do Brasil (SICOOB). Os autores elaboraram 39 indicadores financeiros e chegaram à conclusão de que os mais relacionados à insolvência estão no âmbito da proteção, efetiva estrutura financeira, qualidade dos ativos e taxas de retorno e custo.

Gozer, Gimenes, Menezes, Albuquerque e Isotani (2014) diagnosticaram a insolvência das cooperativas de crédito mútuo do estado do Paraná por intermédio de um modelo matemático com base em redes neurais artificiais (RNA) para grupos de 10, 11 e 27 indicadores do sistema PEARLS. Esse modelo reproduziu o funcionamento do cérebro humano e sua capacidade de absorver informações. Como resultado, constatou-se que a rede RNA com modelagem para os 27 indicadores apresentou os melhores desempenhos.

Silva, Padilha e Silva (2015) elaboraram um ranking das 25 maiores cooperativas de crédito brasileiras entre 2008 e 2012, tendo como base a qualidade dos ativos e as taxas de retorno e custos do sistema PEARLS. Os resultados mostraram que os indicadores do grupo de taxa e retornos de custos, foram os que mais impactaram o ranking. Desta forma, foi observado que a performance econômico-financeira de tais cooperativas possui relação com a eficiência da gestão de controle de custos operacionais.

Com base nos trabalhos anteriores e nas recomendações do Conselho Mundial de Cooperativismo de Poupança e Crédito, optou-se por utilizar os indicadores do sistema PEARLS como variáveis explicativas de risco das cooperativas de crédito, dado pelo beta contábil. Os indicadores do sistema PEARLS são detalhados nas Tabelas de 2 a 7, a seguir. 
Tabela 2

\section{Indicadores de proteção}

\section{P - Proteção}

P1 = Provisão para liquidação duvidosa sob operações de crédito / Carteira classificada total

Objetivo: Medir o volume de provisão de créditos duvidosos em relação à carteira total.

$\mathbf{P 2}$ = Operações de crédito vencidas / Carteira classificada total

Objetivo: Verificar os créditos vencidos em relação à carteira de crédito total.

P3 = Operações de risco nível D até H / Classificação da carteira de crédito

Objetivo: Mostrar a parcela da carteira de crédito com atraso superior a 61 dias.

P4 = Percentual de provisão estimada nível D até H / Patrimônio líquido ajustado

Objetivo: Mostrar a parcela de carteira de crédito classificada com atraso acima de 61 dias em relação ao Patrimônio Líquido Ajustado.

Fonte: Bressan et al. $(2010 ; 2011)$.

Tabela 3

\section{Indicadores de efetiva estrutura financeira}

$\mathbf{E 1}=$ Operações de crédito líquidas / Ativo total

Objetivo: Medir o percentual de ativo total investido na carteira de crédito.

$\mathbf{E 2}=$ Investimentos financeiros / Ativo total

Objetivo: Medir o percentual do ativo total investido em ativos financeiros.

$\mathbf{E 3}=$ Capital social / Ativo total

Objetivo: Medir o percentual do ativo total financiado pelos cooperados.

E4 = Capital institucional / Ativo total

Objetivo: Medir o percentual do ativo total financiado pelo capital institucional (capital da cooperativa, não considerando o capital do cooperado).

E5 = Renda de intermediação financeira / Ativo total médio

Objetivo: Medir a renda de intermediação financeira em relação ao ativo total médio.

E6 = Ativo total / Patrimônio líquido ajustado

Objetivo: Medir a utilização de recursos próprios no financiamento dos ativos detidos pela cooperativa.

Fonte: Bressan et al. $(2010 ; 2011)$.

\section{Tabela 4}

\section{Indicadores de qualidade dos ativos}

\section{A - Qualidade dos ativos}

$\mathbf{A 1}=$ (Ativo permanente + Ativos não direcionados com atividade fim da cooperativa) / Patrimônio líquido ajustado

Objetivo: Medir o nível de uso e recursos próprios com ativos fixos e ativos não direcionados à atividade-fim da cooperativa.

A2 = Ativo permanente / Patrimônio líquido ajustado

Objetivo: Medir o volume de ativo permanente em relação ao patrimônio líquido ajustado.

A3 = Ativos não direcionados com a atividade-fim da cooperativa / Ativo total

Objetivo: Mostrar a relação dos demais ativos em relação ao ativo total.

A4 = Depósitos totais / Ativo total

Objetivo: Mostrar o total de ativos que provêm de depósitos.

Fonte: Bressan et al. $(2010 ; 2011)$. 
Tabela 5

\section{Indicadores de taxas de retorno e custos}

\section{$\mathbf{R}$ - Taxas de retorno e custos}

R1 = Rendas de operações de crédito / Operações de crédito médias

Objetivo: Medir o quanto a carteira de crédito rende.

R2 = Renda líquida de investimento financeiro / Investimento financeiro médio

Objetivo: Medir o quanto os investimentos financeiros rendem.

$\mathbf{R 3}$ = Despesas de depósito a prazo / Depósitos a prazo

Objetivo: Medir o custo dos depósitos a prazo.

R4 = Despesas de obrigações por empréstimos e repasses / Obrigações por empréstimos e repasses médios

Objetivo: Medir o custo dos fundos de empréstimos.

R5 = Margem bruta / Ativo total médio

Objetivo: Saber a relação entre margem bruta e o ativo total médio.

R6 = Despesas operacionais / Ativo total médio

Objetivo: Medir o custo associado com o gerenciamento dos ativos das cooperativas de crédito, indicando o grau de eficiência ou ineficiência operacional.

R7 = Sobras / Ativo total médio

Objetivo: Medir os ganhos da cooperativa.

R8 = Sobras / Patrimônio líquido ajustado

Objetivo: Medir a remuneração do capital próprio.

R9 = Resultado da intermediação financeira / Receita operacional

Objetivo: Medir a relação entre o resultado de intermediação financeira e a receita operacional.

$\mathbf{R 1 0}=$ Sobras / Receita operacional

Objetivo: Medir as sobras em relação à receita operacional.

R11 = Rendas de prestação de serviços / Despesas administrativas

Objetivo: Mostrar quanto as despesas administrativas são cobertas pelas receitas de prestação de serviços.

$\mathbf{R 1 2}$ = Despesas de gestão / Despesas administrativas

Objetivo: Saber o percentual das despesas de gestão em relação ao total das despesas administrativas.

$\mathbf{R 1 3}$ = Despesas administrativas / Ativo total médio

Objetivo: Medir o percentual das despesas administrativas em relação ao ativo total.

Fonte: Bressan et al. $(2010 ; 2011)$.

Tabela 6

\section{Indicadores de liquidez}

L1 = Disponibilidades / Depósitos à vista

Objetivo: Indicador de solvência com o objetivo de mensurar a capacidade da cooperativa em satisfazer seus compromissos imediatos.

$\mathbf{L 2}=$ Ativos de curto prazo / Depósitos totais

Objetivo: Proxy para liquidez corrente.

$\mathbf{L 3}=$ Caixa livre / Ativo total

Objetivo: Mensurar o que há de mais líquido na cooperativa em relação ao ativo.

Fonte: Bressan et al. $(2010 ; 2011)$. 
Tabela 7

\section{Indicadores de sinais de crescimento}

$\mathrm{S}$ - Sinais de crescimento

S1 = Crescimento da receita operacional $=($ Receita operacional do mês corrente $/$ Receita operacional do mês anterior) -1

Objetivo: Medir a taxa de crescimento da receita operacional.

S2 = Crescimento da captação total = (Captação total do mês corrente / Captação total do mês anterior $)-1$

Objetivo: Medir o percentual de crescimento da captação total.

S3 = Crescimento das operações de crédito com nível de risco D-H = (Operações de crédito com nível de risco D-

H do mês corrente / Operações de crédito com nível de risco D-H do mês anterior) - 1

Objetivo: Medir a taxa de crescimento das operações de crédito com risco D-H.

S4 = Crescimento dos ativos não direcionados com atividade-fim da cooperativa (Andaf) = (Andaf do mês corrente

/ Andaf do mês anterior) - 1

Objetivo: Medir a taxa das Andafs.

S5 = Crescimento da provisão sobre operações de crédito de liquidação duvidosa (PECLD) $=$ (PECLD do mês corrente / PECLD do mês anterior) - 1

Objetivo: Medir a taxa de crescimento da PECLD.

S6 = Crescimento das despesas administrativas = (despesas administrativas do mês corrente / despesas administrativas do mês anterior) - 1

Objetivo: Medir o crescimento das despesas administrativas. Quanto menor, melhor.

S7 = Crescimento do Patrimônio Líquido Ajustado (PLA) = (PLA do mês corrente / PLA do mês anterior) - 1

Objetivo: Medir a taxa de crescimento do PLA.

S8 $=$ Crescimento do ativo total $(\mathrm{AT})=($ AT do mês corrente $/$ AT do mês anterior $)-1$

Objetivo: Medir a taxa de crescimento do AT. Deve ser superior à taxa de inflação segundo a WOCCU.

S9 = Crescimento das operações de crédito = (Operações de crédito do mês corrente / Operações de crédito do mês anterior) -1

Objetivo: Medir o crescimento das aplicações de crédito da cooperativa.

Fonte: Bressan et al. $(2010 ; 2011)$.

Dessa forma, se esses indicadores realmente forem adequados para as cooperativas de crédito, isto é, construídos de tal forma que capturem a qualidade da informação contábil, esperase que eles sejam relevantes em determinada medida para explicar o risco dessas entidades.

\subsection{CAPM e Beta Contábil}

Risco é um termo usado de forma corriqueira que continua indefinido ainda nos dias atuais (Rodrigues, Silva, Libonati, \& Pereira, 2008). É considerado uma medida de incerteza em que as possibilidades de retorno são desconhecidas. Segundo Securato (1993), pode ser compreendido como a possibilidade de fracasso em objetivos já estabelecidos. Para Edwards e Bowen (2005), o processo de risco envolve a previsibilidade e o impacto de um evento.

Apesar das inúmeras conceituações existentes sobre risco, todas apontam para a incerteza do que pode vir a ocorrer em determinado evento já preestabelecido. Partindo desse princípio, Sharp (1964), Lintner (1965) e Mossin (1966) desenvolveram o modelo do CAPM (Capital Asset Pricing Model) com base nos trabalhos de Markowitz (1952; 1959), adotando como pressupostos que o mercado é perfeito, os indivíduos racionais e a tomada e concessão de empréstimos ocorrem à taxa livre de risco. Assim, vigorando tais critérios, a expectativa de retorno de um ativo poderia ser representada como a esperança do retorno de um ativo livre de risco somado a um prêmio de risco, conforme a Equação (1).

$$
E\left(R_{i}\right)=E\left(R_{z m}\right)+\left[E\left(R_{m}\right)-E\left(R_{z m}\right)\right] \beta_{i m}
$$

Enquanto Lintner (1965) considera que a parcela $E\left(R_{z m}\right)$ trata simplesmente da taxa livre de risco, com $E\left(R_{m}\right)-E\left(R_{z m}\right)$ capturando o prêmio por unidade de risco de beta $(\beta)$, Black (1972) acredita que a primeira parcela citada diz respeito ao menor retorno esperado pelo mercado, enquanto a segunda reflete o prêmio pelo beta positivo. 
De outra maneira, o modelo do CAPM considera, ainda, que o risco total de um ativo é dado pela soma de seu risco não diversificável (sistêmico) com seu risco diversificável (não sistêmico). Na visão de Rodrigues et al. (2008), o modelo do CAPM pressupõe que os investidores racionais estarão sujeitos apenas ao risco não diversificável, uma vez que procurarão diversificar seu portfólio mitigando ou eliminando o risco diversificável.

$\mathrm{Na}$ equação do modelo do CAPM, o risco não diversificável possui sua representação no beta e relaciona-se de forma positiva e linear com o retorno esperado. O coeficiente beta, popularmente conhecido como beta de mercado, pode ser expresso pela Equação (2):

$$
\beta_{i}=\frac{\operatorname{Cov}\left(R_{i}, R_{m}\right)}{\sigma^{2}\left(R_{m}\right)}
$$

onde $\operatorname{Cov}\left(R_{i}, R_{m}\right)$ é a covariância entre o retorno do ativo $i$, e o retorno da carteira de mercado $m$ e $\sigma^{2}\left(R_{m}\right)$ é a variância do mercado.

A interpretação para o $\beta$ ocorre da seguinte forma: se o risco do ativo $i$ for igual ao da carteira de mercado $m$, o retorno de seu $\beta$ será igual a 1 ; se o risco do ativo $i$ for maior que o da carteira de mercado $m$, seu $\beta$ será maior que 1 , indicando maior retorno; por sua vez, caso o risco do ativo $i$ seja menor que o da carteira de mercado $m$, seu $\beta$ será menor que 1 , evidenciando menor retorno.

Analogamente ao beta de mercado, existe o chamado beta contábil, que se utiliza dos dados contábeis para mensurar a variação de risco de empresas cujas ações possuem pouca liquidez ou não sejam negociadas em bolsa. A hipótese básica desse modelo é que, se os lucros contábeis conseguem prever os fluxos de caixa futuros, o beta contábil é um bom estimador para o beta de mercado de determinada empresa (Watts \& Zimmerman, 1986).

No que tange aos estudos que tratam sobre as relações entre informações contábeis e o retorno de ativos financeiros, o trabalho pioneiro de Ball e Brown (1969) analisou 261 empresas entre os anos 1946 e 1966, tendo observado uma relação entre lucro líquido, lucro operacional e lucro por ação com o beta de mercado dessas empresas.

Beaver, Kettler e Scholes (1970) identificaram correlações significativas entre dados contábeis com a elaboração de índices que poderiam indicar o risco de falência de determinada firma, observando que as variáveis contábeis auxiliaram na previsão de risco.

Bowman (1979) mostrou a relação entre variáveis contábeis e a mensuração do risco de mercado. Seu estudo analisou a relação entre as variáveis financeiras: alavancagem, risco de falência, juros, beta contábil, variação dos lucros, dividendos, tamanho e crescimento da empresa, e sua relação com o risco não diversificável do mercado. Através dessa análise, concluiu que há uma relação entre o risco não diversificável, a alavancagem e o beta contábil.

Por outro lado, diversos estudos, como os de Breen e Lerner (1973), Gonedes (1973), Lev e Kunitzky (1974) e Elgers (1980), não detectaram relações significativas entre informações contábeis e o beta de mercado.

No Brasil, Rodrigues et al. (2008) sugeriram que o beta contábil fosse calculado a partir dos lucros e não dos retornos, sendo o lucro de cada empresa regredido contra os lucros do setor que melhor representasse onde a empresa está inserida. Seus resultados mostraram que o beta de mercado não difere estatisticamente do beta contábil.

Já Fernandes, Galdi, Teixeira e Teixeira (2008) usaram dois betas contábeis para efeito de comparação com o beta de mercado, considerando as ações das 50 empresas de capital aberto mais líquidas negociadas na Bolsa de Valores de São Paulo (Bovespa). Para o primeiro beta contábil, relacionou-se a covariância entre o retorno contábil de cada empresa e o retorno contábil mediano de todas as empresas da amostra, sendo o denominador dado pela variância do retorno contábil mediano de toda a amostra. $\mathrm{O}$ segundo beta contábil relacionou a covariância entre o retorno contábil de cada empresa e o retorno de mercado trimestral do índice Bovespa (Ibovespa), considerando a variância do retorno trimestral do Ibovespa como divisor. Os autores concluíram que o beta contábil pode ser um substituto do beta de mercado. 
Amorim, Lima e Pimenta Junior (2014) selecionaram 87 empresas de 15 setores listadas na BM\&FBOVESPA considerando dados do período 1995-2013. Utilizou-se a regressão do retorno dos títulos e do Ibovespa para calcular os betas de mercado e 14 variáveis contábeis para os betas contábeis. A correlação de Person mostrou que os betas contábeis podem ser utilizados como proxy para os betas de mercado sob certas condições.

Antunes e Guedes (2006) investigaram se o indicador contábil de alavancagem pode ser utilizado como aproximação do risco do beta de mercado. Foram realizados testes de correlação, regressão linear e análise visual da dispersão entre a alavancagem (total e financeira) e o beta de todas as empresas listadas na Bovespa. Todos os indicadores foram coletados na Economática para o período de 1995 a 2005 e os resultados indicaram ausência de relação entre as variáveis.

Em outras palavras, apesar de terem sido desenvolvidos diversos estudos nacionais e internacionais associando as informações contábeis (betas contábeis) e os betas de mercado, os dados não são conclusivos e não há consenso quanto a essa relação (Amorim et al., 2014). Contudo, como as cooperativas de crédito são entidades que não possuem ações negociadas em bolsa, o beta contábil será adotado como proxy em lugar do beta de mercado, já que as informações contábeis dessas entidades são sua única fonte de dados consistentes.

\section{METODOLOGIA}

Foram analisados os dados públicos trimestrais das cooperativas de crédito presentes no sistema IF.data do BACEN entre 2010 e 2018. Inicialmente, efetuou-se o cálculo do beta contábil, que é o indicador de risco dessas entidades. Para tanto, a receita trimestral entre 2010 e 2018 foi utilizada como proxy para o retorno das cooperativas. O retorno do mercado foi construído com base na mediana da receita trimestral de todas as cooperativas em cada trimestre, conforme proposto por Fernandes et al. (2008), resultando em 2.491 cooperativas de crédito singulares com dados para pelo menos um trimestre.

Entretanto, como nem todas as cooperativas possuíam observações entre o $1^{\circ}$ trimestre de 2010 e o $4^{\circ}$ trimestre de 2018 (36 trimestres), realizou-se um recorte nos dados, a fim de excluir as cooperativas que tivessem menos de 30 trimestres com dados. Tal procedimento é recomendado por autores como Fávero (2015) e Gujarati e Porter (2011), para os quais uma regressão deve apresentar no mínimo 30 observações, com o intuito de manter uma qualidade mínima para o seu cálculo.

Restaram, assim, 496 cooperativas na amostra para a estimativa do modelo. Definida a série histórica da receita trimestral de cada uma das cooperativas, calculou-se o retorno trimestral de cada uma delas a partir da Equação (3):

$$
\text { Retorno trimestral }=L N\left(\text { Receita } \text { trimestral }_{t} /{\text { Receita } \left.\text { trimestral }_{t-1}\right)}\right.
$$

Por sua vez, o retorno do mercado foi calculado a partir da mediana dos retornos trimestrais das cooperativas, seguindo a mesma fórmula. Calculadas as séries de retorno de cada uma das cooperativas e do mercado, foi possível elaborar o beta contábil de cada uma das cooperativas conforme a Equação (2) apresentada na Seção 2.3.

Foram selecionados todos os indicadores do sistema PEARLS para os quais o sistema IF.data do BACEN continha informações. Além disso, alguns desses indicadores precisaram ser adaptados para refletir melhor a realidade. Por exemplo, os indicadores R1 e R4 tiveram seus denominadores originais substituídos pelo ativo total, pois as cooperativas de crédito possuem ativos muito "inflados", o que captura melhor a rentabilidade e as despesas em relação aos investimentos.

Os indicadores adaptados utilizados na pesquisa correspondem a um total de 15 indicadores, os quais são apresentados na Tabela 8, a seguir. 
Tabela 8

\section{Indicadores adaptados do sistema PEARLS}

\begin{tabular}{l}
\hline P1 = Provisão de crédito / Operações de crédito \\
\hline E1 = (Operações de crédito líquidas + Outros créditos líquidos e provisão) / Ativo total \\
\hline E5 = Receitas de intermediação financeira / Ativo total \\
\hline E6 = Ativo total / Patrimônio líquido \\
\hline A4 = Depósito total / Ativo total \\
\hline R1 = Rendas de operações de crédito / Ativo total \\
\hline R4 = Despesas de obrigações por empréstimos e repasses / Ativo total \\
\hline R6 = Despesas operacionais / Ativo total \\
\hline R7 = Sobras (resultado antes da tributação) / Ativo total \\
\hline R8 = Sobras (resultado antes da tributação) / Patrimônio líquido \\
\hline R9 = Resultado de intermediação financeira / Receita operacional \\
\hline R10 = Sobras (resultado antes da tributação) / Receita operacional \\
\hline R11 = Rendas de prestação de serviços / Despesas administrativas \\
\hline R12 = Despesas de pessoal / Despesas administrativas \\
\hline R13 = Despesas administrativas / Ativo total \\
\hline Fonte: Elaboração dos autores.
\end{tabular}

Antes da aplicação do modelo econométrico, foram calculadas as estatísticas descritivas dos indicadores. Além disso, foi construída uma tabela de correlação para todas as variáveis empregadas na pesquisa. Essa tabela de correlação buscou averiguar dois aspectos dos dados. Primeiro, o poder potencial de explicação das variáveis independentes; segundo, uma eventual presença de multicolinearidade entre algumas variáveis. $\mathrm{O}$ modelo econométrico foi construído segundo a Equação (4):

$$
\beta_{\text {contábil }}=\beta_{0}+\sum_{n=1}^{15} B_{n} \text {.Indicadores PEARLS } S_{i t}+\varepsilon_{i}
$$

onde $\beta$ contábil ${ }_{i t}$ refere-se à variável dependente, ou seja, o beta contábil das cooperativas; $\sum_{n=1}^{15} B_{n}$. Indicadores $P E A R L S_{i t}$ diz respeito a cada um dos 15 indicadores PEARLS para cada uma das cooperativas; e $\varepsilon_{i}$ representa o termo de erro aleatório, com média zero e variância constante.

Desse modo, para determinar se os indicadores contábeis propostos pelo sistema PEARLS estão relacionados com o risco das cooperativas de crédito brasileiras, é preciso avaliar não somente a qualidade das variáveis independentes individualmente, mas também a capacidade explicativa das variáveis em conjunto sobre o beta contábil, o que significa a rejeição da hipótese nula para a estatística $\mathrm{F}$ e a existência de poder explicativo no $\mathrm{R}^{2}$ da regressão.

\section{RESULTADOS E DISCUSSÃO}

Inicialmente, foram elaboradas as estatísticas descritivas (média, desvio padrão, máximo, mínimo, curtose e assimetria) para os 15 indicadores baseados no sistema PEARLS, bem como para o beta contábil que foi calculado. A Tabela 9 sintetiza os resultados para as estatísticas descritivas. 
Tabela 9

Estatísticas descritivas

\begin{tabular}{ccccccccc}
\hline & Beta contábil & P1 & E1 & E5 & E6 & A4 & R1 & R4 \\
\hline Média & 2,413 & 0,188 & 1,818 & 0,204 & 12,346 & 1,332 & 0,179 & $-0,005$ \\
\hline Desvio padrão & 7,042 & 0,261 & 1,073 & 0,144 & 11,163 & 1,274 & 0,143 & 0,009 \\
\hline Máximo & 94,200 & 2,411 & 3,960 & 0,992 & 55,449 & 3,816 & 0,975 & 0,006 \\
\hline Mínimo & $-0,072$ & 0,000 & 0,000 & 0,000 & $-0,004$ & 0,000 & 0,000 & $-0,049$ \\
\hline Curtose & 92,284 & 26,343 & $-0,822$ & 3,936 & $-0,078$ & $-1,563$ & 4,488 & 5,012 \\
\hline Assimetria & 8,119 & 4,190 & $-0,510$ & 1,123 & 0,793 & 0,232 & 1,478 & $-2,275$ \\
\hline \hline Média & $\mathbf{R 6}$ & $\mathbf{R 7}$ & $\mathbf{R 8}$ & $\mathbf{R 9}$ & $\mathbf{R 1 0}$ & $\mathbf{R 1 1}$ & $\mathbf{R 1 2}$ & $\mathbf{R 1 3}$ \\
\hline Desvio padrão & 0,169 & 0,084 & 0,354 & 481,445 & 317,853 & 1,025 & 3,555 & 0,167 \\
\hline Máximo & 0,000 & 0,541 & 4,136 & 5591,276 & 3954,381 & 1,252 & 30,168 & 2,372 \\
\hline Mínimo & $-1,243$ & $-0,478$ & $-3,404$ & $-2,689$ & $-215,202$ & $-6,143$ & $-16,623$ & $-0,655$ \\
\hline Curtose & 10,467 & 12,705 & 81,328 & 79,644 & 103,081 & 1,707 & 13,212 & 142,050 \\
\hline Assimetria & $-2,753$ & $-0,827$ & 1,397 & 8,392 & 9,651 & $-1,173$ & 1,312 & 9,010 \\
\hline Fon & & & & & & $-0,886$ & 3,956 & $-0,064$ \\
\hline
\end{tabular}

Fonte: Elaborado pelos autores.

O primeiro aspecto que nos chamou a atenção diz respeito ao indicador beta contábil, que revelou um valor médio da ordem de 2,41. Como esse valor varia entre -0,072 e 94,2, sugere-se que as cooperativas de crédito singulares apresentam elevado nível de risco. Em termos de comparação, mesmo as empresas de capital aberto mais arriscadas tendem a apresentar betas com valores não muito superiores a um.

Com relação aos indicadores do sistema PEARLS, destaca-se um para cada dimensão:

a) $\mathrm{O}$ indicador de proteção (P1) mostrou que, em cada operação de crédito realizada, as cooperativas de crédito constituíram, em média, quase $19 \%$ de provisões para créditos de liquidação duvidosa. Isso indica que elas tendem a apresentar elevado nível de inadimplência se comparadas aos bancos, que reconhecem em média 5\% de suas provisões em créditos de liquidação duvidosa, conforme Dantas et al. (2017).

b) $\mathrm{O}$ indicador de estrutura financeira (E1) evidenciou que todos os créditos líquidos somados às suas provisões corresponderam em torno de 1,82 vezes o ativo total dessas entidades.

c) O indicador de qualidade do ativo (A4) revelou que os depósitos totais representaram aproximadamente 1,33 vezes o volume de ativos das cooperativas.

d) Por fim, o indicador de taxa de retorno e custo (R1) manifestou que as rendas obtidas pelas cooperativas com operações de crédito representaram quase $18 \%$ de seus ativos.

Pode-se perceber, a partir dessa análise, que a questão do crédito desempenha papel fundamental na estrutura financeira-contábil das cooperativas. Segundo Sehn e Carlini Jr. (2007), uma das maiores preocupações das organizações, independente de tamanho, é a questão da inadimplência. Com o objetivo de diminuir tais riscos, as instituições financeiras desenvolvem políticas de mitigação de risco para reinvestir seu capital futuramente (Amaral Jr. \& Távora Jr., 2010).

Outro ponto que fica claro ao analisar a distribuição das variáveis estudadas é que a maioria delas tem alta curtose (distribuição leptocúrtica) e assimetria, fato que sugere a não normalidade das distribuições, assim como um alto desvio padrão em relação à média, também observado pela amplitude da distribuição (diferença entre os valores mínimo e máximo). Ainda que sejam pontos de preocupação na estimativa do modelo, não foi necessário qualquer tipo de ajuste no que tange à questão da normalidade, em virtude do tamanho da amostra (superior a 400 observações) e da não observância de impactos na regressão. 
Em seguida, calculou-se a correlação entre as variáveis do estudo, com a intenção de avaliar o potencial de explicação das variáveis independentes quando da elaboração da regressão para o beta contábil. Os resultados são apresentados na Tabela 10.

Tabela 10

Correlação dos indicadores PEARLS com o beta contábil

\begin{tabular}{|c|c|c|c|c|c|c|c|c|}
\hline & Beta contábil & P1 & E1 & E5 & E6 & A4 & R1 & $\mathbf{R 4}$ \\
\hline P1 & 0,009 & 1 & & & & & & \\
\hline E1 & $-0,075$ & 0,255 & 1 & & & & & \\
\hline $\mathbf{E 5}$ & $-0,096$ & 0,568 & 0,722 & 1 & & & & \\
\hline E6 & 0,108 & 0,176 & 0,298 & 0,130 & 1 & & & \\
\hline A4 & 0,189 & 0,268 & 0,213 & 0,233 & 0,800 & 1 & & \\
\hline $\mathbf{R 1}$ & $-0,117$ & 0,552 & 0,718 & 0,989 & 0,049 & 0,142 & 1 & \\
\hline $\mathbf{R 4}$ & $-0,042$ & $-0,066$ & $-0,338$ & 0,016 & $-0,483$ & $-0,205$ & 0,022 & 1 \\
\hline R6 & 0,145 & $-0,558$ & $-0,458$ & $-0,825$ & $-0,016$ & $-0,062$ & $-0,838$ & $-0,093$ \\
\hline $\mathbf{R 7}$ & 0,018 & $-0,361$ & 0,230 & 0,015 & $-0,021$ & $-0,120$ & $-0,003$ & 0,072 \\
\hline $\mathbf{R 8}$ & 0,071 & $-0,290$ & 0,115 & 0,008 & 0,200 & 0,182 & $-0,016$ & $-0,026$ \\
\hline R9 & $-0,038$ & $-0,043$ & 0,142 & 0,058 & $-0,125$ & $-0,150$ & 0,052 & 0,101 \\
\hline $\mathbf{R 1 0}$ & $-0,021$ & $-0,056$ & 0,112 & 0,023 & $-0,102$ & $-0,135$ & 0,018 & 0,080 \\
\hline R11 & $-0,114$ & $-0,130$ & $-0,264$ & $-0,073$ & $-0,661$ & $-0,543$ & $-0,012$ & 0,561 \\
\hline R12 & $-0,063$ & 0,147 & 0,507 & 0,361 & 0,232 & 0,211 & 0,324 & $-0,100$ \\
\hline \multirow[t]{2}{*}{ R13 } & 0,061 & $-0,312$ & $-0,241$ & $-0,472$ & 0,118 & $-0,056$ & $-0,473$ & $-0,049$ \\
\hline & R6 & R7 & R8 & R9 & R10 & R11 & R12 & R13 \\
\hline R6 & 1 & & & & & & & \\
\hline R7 & 0,253 & 1 & & & & & & \\
\hline $\mathbf{R 8}$ & 0,082 & 0,567 & 1 & & & & & \\
\hline R9 & 0,046 & 0,159 & 0,004 & 1 & & & & \\
\hline R10 & 0,080 & 0,191 & 0,014 & 0,966 & 1 & & & \\
\hline R11 & $-0,058$ & $-0,071$ & $-0,162$ & 0,160 & 0,121 & 1 & & \\
\hline R12 & $-0,163$ & 0,174 & 0,051 & 0,167 & 0,143 & $-0,225$ & 1 & \\
\hline R13 & 0,455 & 0,458 & 0,612 & 0,018 & 0,040 & $-0,011$ & $-0,056$ & 1 \\
\hline
\end{tabular}

Fonte: Elaborado pelos autores.

As variáveis independentes com correlações mais fortes com a variável dependente, isto é, o beta contábil, foram A4, R6 e R11. Por sua vez, foram avaliadas as correlações entre as variáveis independentes, com o objetivo de combater potenciais problemas de multicolinearidade. Assim, foram excluídos alguns indicadores do sistema PEARLS: a) R1 e E5, que apresentaram fortes correlações com E1 e R6, optando-se por manter esses dois últimos, dada sua maior correlação com a variável dependente; e b) R10, que revelou elevada correlação com R9, tendo sido excluído o primeiro por apresentar correlação mais fraca com o beta contábil.

Ao final das exclusões, restaram 12 indicadores que foram utilizados para tentar explicar o beta contábil (risco) das cooperativas. Os resultados obtidos são apresentados na Tabela 11. 
Tabela 11

Regressão explicando o beta contábil com dados limpos

\begin{tabular}{|c|c|c|}
\hline \multicolumn{3}{|c|}{$\beta$ contábil $=\beta o+\sum B_{n}$. Indicadores PEARLS $i+\varepsilon$} \\
\hline Variável & Estimador & Erro padrão \\
\hline Intercepto & 2,454 & $0,0002 * * *$ \\
\hline P1 & 2,392 & $1,419 *$ \\
\hline E1 & $-0,296$ & 0,332 \\
\hline E6 & $-0,105$ & 0,075 \\
\hline A4 & 1,687 & $0,719 * *$ \\
\hline R4 & $-37,015$ & 37,136 \\
\hline R6 & 6,793 & $2,471 * * *$ \\
\hline R7 & 3,917 & 4,212 \\
\hline R8 & 0,965 & 1,027 \\
\hline R9 & 0,00007 & 0,0001 \\
\hline R11 & $-0,195$ & 0,689 \\
\hline R12 & $-0,150$ & 0,204 \\
\hline $\mathrm{R} 13$ & $-0,762$ & 1,531 \\
\hline \multicolumn{3}{|l|}{$\mathrm{F}=2,27(0,0090)$} \\
\hline \multicolumn{3}{|l|}{$\mathrm{R}^{2}=0,081$} \\
\hline $\mathrm{R}^{2}$ ajust $=0,045$ & & \\
\hline
\end{tabular}

Nota. O erro padrão foi reestimado considerando a matriz HAC. Significância * $10 \%$, ** 5\% e *** $1 \%$.

Fonte: Elaborado pelos autores.

Em primeiro lugar, avaliou-se a base de dados da regressão quanto a possíveis problemas de heterocedasticidade e autocorrelação. Para a primeira, aplicou-se o teste de Breush-Pagan, que apresentou $\chi^{2}=5,20$, com probabilidade associada de 0,951 , o que não permite a rejeição da hipótese nula de homocedasticidade. No que diz respeito à autocorrelação, foi elaborado o teste de Durbin-Watson, que resultou em um $\mathrm{DW}=1,91$, com probabilidade associada de 0,188 , não sendo possível a rejeição da hipótese nula de que os dados não possuem autocorrelação ao longo do tempo.

De forma geral, é possível verificar que as variáveis independentes analisadas em conjunto são relevantes para o beta contábil das cooperativas de crédito, pois a estatística $\mathrm{F}$ foi significante a $1 \%$, manifestando que o conjunto de variáveis é importante para explicar o beta contábil. Este é um primeiro argumento favorável à qualidade da informação contábil contida nos indicadores PEARLS. Além disso, o R ${ }^{2}=0,081$ expressa que $8,1 \%$ do beta contábil das cooperativas de crédito pode ser explicado pelos indicadores propostos, evidenciando que a informação contábil contida nos indicadores financeiros contribui com a explicação do risco dessas entidades, mesmo que em pequena medida.

Seria possível pensar que um baixo $\mathrm{R}^{2}$ poderia representar um problema. Contudo, diversos trabalhos que construíram o beta contábil como proxy para o beta de mercado, considerando diferentes amostras de empresas em diversos países, revelaram um valor reduzido para essa estatística. Por exemplo, Breen e Lerner (1973) em suas estimativas encontraram valores de $\mathrm{R}^{2}$ que variaram entre $6 \%$ e $54 \%$, com diversos coeficientes não sendo estatisticamente diferentes de zero. Os vários modelos elaborados por Lima, Ilha e Galdi (2009) apresentaram valores de R ${ }^{2}$ entre 6,1\% e 59,5\%. Já Amorim, Lima e Murcia (2012) acharam em suas estimativas valores de $\mathrm{R}^{2}$ que se encontravam no intervalo de $6,2 \%$ a $39,46 \%$, com muitos dos coeficientes testados não apresentando significância estatística, o que indica que o $\mathrm{R}^{2}$ não deve ser analisado de forma isolada, mas em conjunto com as demais estatísticas do modelo.

Por sua vez, dos doze indicadores do sistema PEARLS utilizados para explicar o risco das cooperativas de crédito, apenas P1, A4 e R6 foram estatisticamente significantes. O indicador P1 mostrou que o percentual de recursos provisionados em relação às operações de crédito é importante para explicar o risco de uma cooperativa. O sinal positivo do coeficiente de P1 indica 
que o mercado entende que entidades com maiores provisões para créditos de liquidação duvidosa apresentam maiores níveis de risco que as demais, pois a inadimplência esperada tende a ser maior.

O coeficiente da variável A4 (depósitos totais sobre ativo total) apresentou sinal positivo, conforme o esperado. Isso sugere que cooperativas com volume elevado de depósitos sobre seu total de ativos tendem a ser mais arriscadas que as demais, de modo que as cooperativas mais alavancadas estão sujeitas ao risco sistêmico do mercado em maior medida.

Por sua vez, o coeficiente da variável R6 (despesas operacionais sobre patrimônio líquido) também foi positivo, o que evidencia que cooperativas de crédito com elevadas despesas operacionais, ou seja, com maior ineficiência, geram maiores riscos para seus associados e seus tomadores de crédito. A esse respeito, Ferreira, Gonçalves e Braga (2007) argumentam que a diminuição de despesas operacionais promove o crescimento da empresa, reduzindo seu risco, com consequentemente melhoria dos serviços disponíveis aos seus cooperados.

Em outras palavras, os resultados confirmam, de forma geral, que a informação contábil utilizada na construção dos indicadores PEARLS são úteis, pois, do contrário, tais indicadores não seriam significantes em conjunto para explicar o beta contábil das cooperativas de crédito, isto é, seu risco.

\section{CONSIDERAÇÕES FINAIS}

O presente estudo buscou investigar se os indicadores contábeis propostos pelo sistema PEARLS efetivamente guardam relação com o risco das cooperativas de crédito brasileiras. A aplicação do sistema PEARLS adaptado à realidade brasileira por Bressan et al. (2010), direcionado à análise de risco das cooperativas de crédito singulares, considera as características de proteção, efetiva estrutura financeira, qualidade dos ativos, taxa de retorno e custos, liquidez e, sinais de investimentos, relevantes para os seus associados, tomadores e órgãos de regulação e fiscalização. Além disso, tal sistema mostra-se como o mais adequado ao mercado cooperativista (WOCCU, 2019).

Os resultados encontrados no presente trabalho evidenciaram a importância da análise da provisão para perdas com créditos de liquidação duvidosa, ou probabilidade de inadimplência de clientes (P1), do fluxo monetário de depósitos presentes nas cooperativas (A4) e das despesas operacionais (R6). Todos os coeficientes dessas variáveis apresentaram sinais positivos, indicando que a probabilidade de inadimplência, o volume de depósitos e os gastos operacionais influenciam o aumento do risco dessas entidades.

Para instituições financeiras, as questões envolvendo indicadores de despesas operacionais, depósitos e, sobretudo, inadimplência de clientes são relevantes para seu sucesso financeiro. A função básica das instituições financeiras é prover recursos de médio a longo prazo para terceiros (Resolução CMN 2.099, 1994). No que diz respeito ao modelo contábil, tais valores acumulados de provisão de crédito e despesas operacionais podem vir a ser um problema grave para a continuidade das cooperativas perante as normas do BACEN. Portanto, devem ser avaliados pelos gestores e demais usuários das informações contábeis. Já para a variável depósitos, pode-se deduzir que maiores volumes de recursos monetários, ao mesmo tempo que elevam o risco de crédito, também permitem que as cooperativas invistam com mais capilaridade no auxílio aos cooperados pertencentes às populações mais necessitadas no território nacional.

Essas evidências mostram que esses três indicadores são os mais importantes para todos aqueles que demandam informações financeiras sobre as cooperativas de crédito. Essa percepção é corroborada em parte pelos estudos de Bressan et al. (2014) para a variável P1, Bressan, Lopes e Menezes (2013) quanto à variável A4, e Silva, Padilha e Silva (2015) no que se refere à variável R6. Portanto, essas variáveis merecem maior atenção dos usuários das informações contábeis, por apresentarem maiores riscos à sociedade. Isso é especialmente importante para a população dos municípios brasileiros de baixa renda, que muitas vezes dependem exclusivamente das cooperativas de crédito para terem acesso a recursos financeiros na forma de empréstimos. 
Além disso, o modelo retratou que todas as variáveis foram relevantes para explicar o beta contábil das cooperativas de crédito. Isso evidencia que a informação contábil contida nos indicadores PEARLS é de qualidade, sendo útil para seus usuários avaliarem o risco de crédito de uma determinada cooperativa.

Durante o desenvolvimento do estudo, pôde-se perceber a relevância das demonstrações contábeis como ferramenta analítica e gerencial para os gestores das cooperativas, seus associados e órgãos de regulação e fiscalização. Comprovou-se que informações contábeis de qualidade permitem analisar tendências futuras por meio da avaliação ocorrida em eventos passados, conforme Fagundes et al. (2008).

Para pesquisas futuras, sugere-se uma análise do beta contábil das cooperativas de crédito centrais, tendo em vista que essas instituições desempenham papel significativo na solidez de todo o sistema financeiro cooperativo, por meio de serviços como centralização financeira, supervisão, assessoria jurídica e contábil, entre outros.

\section{REFERENCIAS}

Almada, S. R., Abreu, M. C. S., Cunha, L.T., Silva Filho, J. C. L. (2011). Desafios para a formação de cooperativas agrícolas na cadeia de suprimento de biodiesel no estado do Ceará. Revista Reuna, 16(4), 13-26.

Amaral Jr, J. B., \& Távora Jr, J. L. (2010). Uma análise do uso de redes neurais para a avaliação do risco de crédito de empresas. Revista do BNDES, 34, 133-180.

Amorim, A. L. G. C., Lima, I. S., \& Pimenta Junior, T. (2014). Informação Contábil e Beta de Mercado. Revista Universo Contábil, 10(4), 128-143.

Amorim, A. L. G. C., Lima, I. S., \& Murcia, F. D. R. (2012). Análise da relação entre as informações contábeis e o risco sistemático no mercado brasileiro. Revista de Contabilidade e Finanças, 23(60), 199-211.

Antunes, G. A., \& Guedes, G. R. (2006). Risco de insolvência e risco sistemático: relação teórica não verificada na Bovespa. Revista de Administração de Empresas, 46(edição especial), 58-71.

Ball, R., \& Brown, P. (1969). Portfolio theory and accounting theory. Journal of Accounting Research, 7(2), 300-323.

Banco Central do Brasil (BACEN) (2019). If.Data. Recuperado em 28 agosto, 2019, de https://www3.bcb.gov.br/ifdata/

Banco Central do Brasil (BACEN) (2018). Participação das cooperativas no mercado de crédito. Estudos Especiais do Banco Central no 14, 2018.

Beaver, W. H., Kettler, P., \& Scholes, M. (1970). The association between market determined and accounting determined risk measures. The Accounting Review, 45(4), 654-681.

Beaver, W. H., \& Manegold, J. (1975). The association between market-determined and accounting determined measures of systematic risk: some further evidence. Journal of Financial and Quantitative Analysis, 10(2), 231-284.

Bowman, R. G. (1979). The theoretical relationship between systematic risk and financial (accounting) variables. The Journal of Finance, 34(3), 917-630. 
Black, F. (1972) Capital Market Equilibrium with Restricted Borrowing. The Journal of Business, 45(3), 444-455.

Breen, W. J., \& Lerner, E. M. (1973). Corporate financial strategies and market measures of risk and return. Journal of Finance, 28(2), 339-351.

Bressan, V. G. F., Braga, M. J., Bressan, A. A., \& Resende Filho, M. A. (2010). Uma proposta de indicadores contábeis aplicados às cooperativas de crédito brasileiras. Revista de Contabilidade e Controladoria, 2(4), 58-80.

Bressan, V. G. F., Braga, M. J., Bressan, A. A., \& Resende Filho, M. A. R. (2011). Uma aplicação do sistema PEARLS às cooperativas de crédito brasileiras. Revista de Administração, 46(3), 258-274.

Bressan, V. G. F., Lopes, A. L. M., \& Menezes, M. R. (2013). Análise de eficiência das cooperativas de crédito brasileiras utilizando informações contábeis. Anais do Congresso Integrado de Contabilidade, Governador Valadares, Minas Gerais, de 24 a 25 de outubro de 2013, 1 .

Bressan, V. G. F., Bressan, A. A., Oliveira, P. H. M., \& Braga, M. J. (2014). Quais indicadores contábeis financeiros do sistema PEARLS são relevantes para análise de insolvência das cooperativas centrais de crédito no Brasil? Revista Contabilidade Vista \& Revista, 25(1), 7498.

Damodaram, A. (1997). Avaliação de Investimentos. Rio de Janeiro: Qualitymark.

Dantas, J. A., Micheletto, M. A., Cardoso, F. A., \& Freire, A. A. P. F. S. (2017). Perdas em créditos nos bancos brasileiros: modelos de perdas esperadas e de perdas incorridas e impactos da IFRS 9. Gestão, Finanças e Contabilidade, 7(2), 156-175.

Dechow, P. M., Ge, W., \& Schrand, C. (2010). Understanding earnings quality: a review of the proxies, their determinants and their consequences. Journal of Accounting and Economics, 50, 344-401.

Duarte, F. C. L., \& Lucena, W. G. L. (2018). A qualidade da informação contábil e a precificação do retorno em excesso no mercado brasileiro de capitais. Revista Contemporânea de Contabilidade, 35(15), 161-178.

Edwards, P. J., \& Bowen, P. A. (2005). Risk Management in Project Organization. University of New South, Australia: Wales Press Ltd.

Elgers, P. (1980). Accounting based risk predictions: a re-examination. The Accounting Review, 55(3), 389-408.

Fagundes, J.A, Lirio, L.A.C, Ciupak, C \& Lavarda, C.E.F (2008). Análise das demonstrações contábeis: Reflexos da conjuntura econômico-social no patrimônio de uma cooperativa de crédito - Sicredi Ouro Verde. ConTexto, 8(13).

Fávero, L. P. (2015). Análise de dados: modelos de regressão com Excel, Stata e SPSS. Rio de Janeiro, RJ: Elsevier. 
Fernandes, A. L. M., Galdi, F. C., Teixeira, A. M. C., \& Teixeira, A.C.C. (2008). Teste de aderência entre o beta contábil e o beta de mercado: uma aplicação prática no mercado brasileiro. Anais do Congresso Brasileiro de Contabilidade, Gramado, Rio Grande do Sul, 18.

Ferreira, M. A. M., Gonçalves, R. M. L., \& Braga, M. J. (2007). Investigação do desempenho das cooperativas de crédito de Minas Gerais por meio da análise envoltória de dados (DEA). Economia Aplicada, 11(3), 1-14.

Gonçalves, W. D. B., \& Lemes, S. (2018). A Relação dos Gastos com P\&D com a Qualidade da Informação Contábil. Contabilidade Vista \& Revista, 29(2), 68-95.

Gonedes, N. (1973). Evidence on the information content of accounting massages: accounting based and market-based estimate of systematic risk. Journal of Financial and Quantitative Analysis, 8(3), 407-444.

Gozer, I. C., Gimenes, R. M.T., Menezes, E. A., Albuquerque, A. R. P. L., \& Isotani, S. (2014). Avaliação de insolvência em cooperativas de crédito: uma aplicação de redes neurais artificiais e do sistema PEARLS. Informe GEPEC, 18(1), 6-30.

Gujarati, D. N., \& Porter, D. C. (2011). Econometria básica (5a ed., p. 924). Rio de Janeiro, RJ: AMGH.

Jacques, E. R., \& Gonçalves, F.O. (2016). Cooperativas de crédito no Brasil: evolução e impacto sobre a renda dos municípios brasileiros. Economia e Sociedade, 25(2), 489-509.

Kaplan, R. S., \& Norton, D. P. (1993). Putting the balanced scorecard to work. Harvard Business Review, 71(5), 134-142.

Lei $n^{\circ} 5.764$ de 16 de dezembro de 1971 (1971). Define a Política Nacional de Cooperativismo, institui o regime jurídico das sociedades cooperativas. Recuperado em 04 março, 2019, de https://presrepublica.jusbrasil.com.br/legislacao/109412/lei-5764-71

Lima, S. V., Ilha, H. F., \& Galdi, F. C. Construção empírica e análise teórica do beta contábil: uma investigação no mercado acionário brasileiro sob a ótica de diferentes pressupostos econométricos. Anais do Congresso USP de Controladoria e Contabilidade, USP, São Paulo, SP, Brasil, 2009.

Lintner, J. (1965). The valuation of risk assets and the selection of risky investments in stock portfolios and capital budgets. The Review of Economics and Statistics, 47(1), 13-37.

Lev, B., \& Kunitzky, S. (1974). On the association between smoothing measures and the risk of common stocks. The Accounting Review, 49(2), 259-270.

Markowitz, H. M. (1952). Portfolio selection. Journal of Finance, 7(1), 77-91.

Markowitz, H. M. (1959). Portfolio selection: efficient diversification of investment. New York: John Wiley \& Sons.

Mossin, J. (1966). Equilibrium in a Capital Asset Market, Econometrica, 34(4), 768-783. 
Organização das Cooperativas Brasileiras (OCB) (2019). O que é cooperativismo? Recuperado em 04 março, 2019, de https://www.ocb.org.br/o-que-e-cooperativismo

Pagnussatt, A. (2004). Guia do cooperativismo de crédito. Porto Alegre: Sagra Luzzatto.

Paulo, E. (2007). Manipulação das informações contábeis: uma análise teórica e empírica sobre os modelos operacionais de detecção de gerenciamento de resultados. Tese de Doutorado em Ciências Contábeis, Departamento de Contabilidade e Atuária, Faculdade de Economia, Administração e Contabilidade, Universidade de São Paulo, São Paulo, Brasil.

Portal do Cooperativismo Financeiro. Dados consolidados dos Sistemas Cooperativos. Recuperado em 26 janeiro, 2019, de https://cooperativismodecredito.coop.br/cenariomundial/cenario-brasileiro/dados-consolidados-dos-sistemas-cooperativos/

Rodrigues, R. N., Silva, F. D. C., Libonati, J. J., \& Pereira, D. M. V. G. (2008). Beta contábil versus beta CAPM: uma investigação empírica no mercado financeiro brasileiro. Revista de Contabilidade da UFBA, 2(1), 40-51.

Resolução CMN 2.099 de 1994. Recuperado em 31 maio, 2020, de http://www.bcb.gov.br

Santos, D. C. D., Guimarães, G. O. M., \& Macedo, M. A. S. (2019). Gerenciamento Tributário e Qualidade da Informação Contábil: Análise do Impacto da Agressividade Tributária na Capacidade Informacional do Lucro para o Mercado Brasileiro de Capitais. Pensar Contábil, 21(74), 3-10.

Securato, J. R. (1993). Decisões financeiras em condições de risco. São Paulo: Atlas.

Sehn, C. F. \& Carlini Junior, R. J. (2007). Inadimplência no sistema financeiro de habitação: um estudo junto à Caixa Econômica Federal. Revista de Administração Mackenzie, 8(2), 59-84.

Sharp, W. F. (1964). Capital asset prices: a theory of market equilibrium under conditions of risk. Jornal of Finance, 19(3), 425-442.

Silva, N. G., Cardoso, T. A. O., Martins, L. N. N., Marena, R. C. F., \& Oliveira, T. V. M. (2018). Cooperativa de crédito versus bancos: uma análise comparativa de custo e investimentos em crédito rural. Revista de Administração e Negócios da Amazônia, 10(2), 103-119.

Silva, A., Padilha, E. S., \& Silva, T. P. (2015). Análise da performance econômico-financeira das 25 maiores cooperativas de crédito do Brasil. Desenvolvimento em Questão, 13(32), 303-333.

Vallim, E. L., Macedo, M. A. S., \& Kolozsvari, A. C. (2019). Qualidade da Informação Contábil: o Impacto das Diferenças Temporais do Alongamento dos 'Accruals' em sua Capacidade Preditiva. Pensar Contábil, 21(76), 3-9.

Vasconcelos, R.W.B. (2006). Identificação de indicadores econômico-financeiros para análise de cooperativas de crédito, singulares ou centrais. Departamento de Supervisão Indireta e Gestão da Informação (DESIG), Banco Central do Brasil. Belo Horizonte: BCB, 2006. Não publicado. 
Watts, R. L., \& Zimmerman, J. L. (1986). Positive accounting theory. Englewood Cliffs: Prentice Hall.

World Council of Credit Unions (WOCCU) (2019). Pearls Monitoring System. Recuperado em 09 fevereiro, 2019, de https://www.woccu.org/documents/pearls_monograph 